\title{
LA VERDAD DE LA ESCRITURA: ENTRE TEOLOGÍA DOGMÁTICA Y EXÉGESIS
}

\author{
David de la Torre
}

\section{RESUMEN}

Cada domingo, como lo hicieron nuestros padres, los cristianos de distintas confesiones nos reunimos para leer el texto que narra las acciones y las palabras de Jesús. Este texto es venerado como Palabra de Dios y así canonizado, sin cesar, en la liturgia eucarística. Pero, la relación con él difiere mucho de una confesión a otra y también en el interior de una misma confesión. Uno de los malos entendidos, más grave, en esa relación que tenemos con la Escritura, es el historicismo, es decir, juzgar el texto a partir de los resultados de la ciencia histórica, imaginando que la verdad de esa palabra radica en ser la radiografía exacta de hechos acontecidos y palabras proferidas en el pasado. Si bien el referente histórico es esencial en una religión de encarnación, tenemos que afirmar que la Escritura cristiana, justamente por ser testimonio de la Verdad encarnada en la historia, no puede reducirse a la simple crónica neutra de la vida de Jesús. Es necesario abandonar toda tentación fundamentalista y todo riesgo de doble verdad, y recordar que los evangelios son un testimonio de fe de las primeras comunidades cristianas, cuya experiencia fundadora les obligó a inventar un lenguaje "poietico" capaz de expresar la Verdad inscrita en la historia de Jesús, para que todos los hombres aproximándose a ese texto, puedan descubrir la verdad de su propia existencia a la luz de la Verdad que es el Logos, único exégeta del Padre.

Palabras clave: Evangelio, Exégesis, Método histórico-crítico, Ficción, Verdad.

\section{ABSTRACT}

Every Sunday, as our fathers in faith did,

1 Pontificia Universidad Católica del Ecuador, Facultad de Ciencias Filosofico-Teológicas, Quito, Ecuador (ddelatorre"puce.edu.ec). 
Christians of different confessions gather to read the text that narrates the actions and words of Jesus. This text is revered as the Word of God and thus canonized, unceasingly in the framework of Eucharistic liturgy. But, the relationship with the text differs a lot, not only from one confession to another, but also within the same confession. One of the worst misunderstandings in that relationship that we have with the Scripture is historicism, that is to say; judging the text based on the results of the historical science, imagining that the truth of such word is the exact radiography of events and words uttered in the past. Even though, the historic referent is essential in the context of a religion of incarnation, we have to say that the Christian Scripture, precisely a testimony of the Truth incarnated in history cannot be reduced to a simple neutral chronicle of the life of Jesus. It is necessary to abandon every fundamentalist temptation and every risk of a double truth, and remember that the gospels are testimony of faith of the early Christian communities, whose founding experiences forced them to invent a "poietic" language capable of expressing the Truth engraved in the history of Jesus of Nazareth to enable all men approaching to this text discover the truth of their own existence through the light of the Truth which is the Logos, the only exegete of the Father.

Key words: Gospels, exegesis, historicalcritical method, fiction, Truth.

\section{INTRODUCCIÓN}

Los textos evangélicos que leemos en cada celebración eucarística son, para todos los cristianos, Palabra de Dios. No solo reconocemos que el personaje central de esas narraciones es el Hijo de Dios, sino que esa palabra tiene algo que decirnos a los hombres y mujeres de este siglo. El protestantismo evangélico ha contribuido a hacer del interés por la Biblia una de las grandes constantes de nuestra época. Los católicos buscan conocer la Biblia, sin embargo, los cursos bíblicos que se ofrecen son en general una arqueología del texto bíblico. Nos hacen creer que la verdad del texto se encuentra en su exacta reproducción completa de la historia, reduciéndola a una simple crónica del pasado. Entonces, es necesario que nos preguntemos qué es en definitiva el texto bíblico, para poder así discernir cuál es la hermenéutica adecuada que honre el hecho de que la Palabra de Dios no es un texto, sino una persona, Jesús. 


\section{EXÉGESIS Y DOGMÁTICA: ¿CRÓNICA DE UN DIVORCIO ANUNCIADO?}

En enero de 1988, el cardenal J. Ratzinger pronunció en Nueva York una conferencia sobre las relaciones entre exégesis y teología; comenzaba su intervención haciéndose eco de la obra de $\mathrm{V}$. Soloviev, La Historia del Anticristo, en donde el Anticristo para seducir a los creyentes se presenta como un gran teólogo y sobre todo como un pionero de la exégesis histórico-crítica:

En la Historia del Anticristo de Vladimir Soloviev, el enemigo escatológico del Redentor se hace valer, en particular, ante los creyentes por el hecho de haber conquistado su doctorado de Teología de Tübingen y haber escrito una obra exegética por la que es reconocido como un pionero en este campo. jEl Anticristo, un famoso exegeta! A través de esta paradoja, Soloviev -hace cerca de cien años- pretendía sacar a la luz la ambigüedad que caracteriza el método de la exégesis bíblica. Es casi ya un truismo hablar hoy de la crisis que conoce el método crítico histórico. Sin embargo, comen- zó con un inmenso optimismo² (Ratzinger, 2000: 76).

Este inicio provocante, incluso injusto respecto a la exégesis histórico-critica, nos pone frente al conflicto de interpretación que marca las relaciones entre la teología dogmática y la exégesis histórico-critica. Este conflicto de interpretación no data de hoy, es omnipresente desde hace dos siglos en la reflexión teológica. Lo que es nuevo es que después de un período en el que las antinomias entre estas dos disciplinas parecían haber sido superadas, las tensiones reaparecen. $Y$ reaparecen con tanta fuerza que este conflicto de interpretación, que en muchos aspectos ha sido saludable, corre el riesgo de transformarse actualmente en un franco divorcio. La indiferencia mutua entre la exégesis y la teología puede hacer muchas más devastaciones para la probidad intelectual de la fe cristiana que la discusión más partisana ${ }^{3}$ (Ratzinger, 2000).

2 J. Ratzinger, 2000: 76. El nombre de Vladimir Soloviev (1853-1900) es citado cada vez con más autoridad en el actual debate filosófico y religioso. Juan Pablo II le cita en su encíclica Fe y razón (número 74) como ejemplo de un pensador que ha sabido establecer una relación fecunda entre la filosofía y la fe cristiana. Nacido en Moscú, fue profesor en la Universidad de Moscú y luego en la de San Petersburgo, cargo que tuvo que abandonar por motivos políticos. Sus primeros trabajos se centraron en la metafísica, pero a continuación prevalecieron en él las preocupaciones religiosas. En 1884 escribió "Los fundamentos espirituales de la vida", obra que contiene la Leyenda del Anticristo, narración de estilo autobiográfico, en la que se narra la venida del Anticristo y su derrota por obra del segundo Concilio de Jerusalén.

3 « La separación entre la exégesis y el dogma es ahora total. La Escritura se ha convertido en una palabra del pasado que todo el mundo se esfuerza a su manera de traer al presente (...) Yendo a la deriva, la 
Tanto en el mundo protestante como en el católico, existe la tentación de renunciar a la crítica, esperando así salvar la fe.

J. Ratzinger señalaba, en su conferencia, algunos riesgos de una exégesis histórico-crítica que con todos sus métodos se convirtió, según él, en una verdadera muralla que bloquea a todo "no iniciado" el acceso a la Biblia. Y denunciaba el hecho que los propios iniciados "no leían" más la Biblia ya que estaban demasiado ocupados en decorticarla en pedazos a partir de los cuales supuestamente había sido compuesta. J. Ratzinger incriminaba el desinterés por lo sobrenatural en una exégesis en la cual la hipótesis "Dios" se había vuelto inútil para interpretar el texto bíblico y la multiplicación de hipótesis no hacía más que conducirnos a una "selva de contradicciones".

El más prudente de los teólogos dogmáticos busca una teología lo más independiente posible de la exégesis. ¿Pero qué valor puede tener una teología cortada de sus propios fundamentos? Esta es la razón por la que un enfoque radical, que se llama el "fundamentalismo", comenzó a ganar partidarios que estigmatizan como falsa en sí misma y absurda toda aplicación del método histórico-crítico a la Palabra de Dios. Quieren regresar a la pureza literal de la Biblia, tomarla tal como se pre- senta y tal como lo comprende el lector ordinario (Ratzinger, 2000: 69-70).

Ante la amenaza del fundamentalismo, una tarea se imponía a los ojos de J. Ratzinger: tener en cuenta los innegables descubrimientos del método histórico y, al mismo tiempo, superar sus límites abriéndolo sobre una hermenéutica pertinente. Solo así será posible escuchar verdaderamente el texto bíblico que me suministra un mensaje que no viene de mí mismo y que es Palabra de Vida para el hombre de hoy. El reto es entonces encontrar esta "hermenéutica pertinente".

La tarea que J. Ratzinger asigna a los teólogos y a los exegetas es sin duda necesaria pero, pensando en los cristianos de hoy, no solo por el riesgo del fundamentalismo, sino para evitar que la "doble verdad" se instale entre los cristianos, eso que E. Troeltsch llamaba "la esquizofrenia de los cristianos" en el mundo moderno. En efecto, es como si para los cristianos existiera una "causalidad de domingo" donde, por ejemplo, Jesús resucita a Lázaro, y una "causalidad de los días laborables" donde Lázaro muerto desde hace más de tres días estaría para siempre en su tumba ya que nadie puede volver a la vida luego de haber muerto. ¿Esta escisión de la conciencia

fe se reduce a una especie de filosofía de la vida que cada uno, según sus posibilidades intenta deducir de la Biblia. El dogma, al cual se le negó su fundamento en la Escritura, ya nada significa. La Biblia, que fue separada del dogma, se ha convertido en un documento del pasado; y por lo tanto, pertenece al pasado». J. Ratzinger, 2000: 76. 
puede superarse? ¿La teología puede abandonar la "conciencia pública" de la verdad, para permanecer encerrada en su propia verdad? Si fuera el caso, la fe cristiana se volvería pura y simplemente una secta al margen de la sociedad. Si deja de ser un potencial crítico para el futuro común de la humanidad, se pierde en el relativismo de la sociedad moderna, en donde cada uno puede creer lo que quiera a condición de aceptar que el otro tenga el mismo derecho.

En la búsqueda de una comprensión de la realidad que no esté basada en el arbitrario de nuestras preconcepciones, J. Ratzinger, después de haber hecho un breve cuestionamiento de algunas formas de exégesis (materialistas, feministas, psicológicas...), hace una crítica enérgica de las preconcepciones positivistas de la exégesis histórico-crítica y de su supuesta "inocencia dogmática"4 (Barthes, 1957). En efecto, insertos en historias no estamos nunca al principio del proceso que conduce a la verdad. En todo hombre hay, irreducible al conocimiento y sin común medida con él, una posición adoptada sobre el significado de la realidad tomada como un todo, es decir, una fe que guía sus pensamientos y sus opciones.
Necesitamos una "autocrítica" de la exégesis histórica que pueda prolongarse en una crítica de la razón histórica y que sea pues la continuación y el desarrollo de las críticas kantianas de la razón y del juicio [... ] la autocrítica del método histórico debería comenzar por una lectura diacrónica de sus propias conclusiones; debería así romper incluso con el deseo ilusorio de querer alcanzar esta certeza casi científica con la cual, hasta ahora, se presentaron generalmente sus interpretaciones. De hecho, a la base del método históricocrítico se encuentra el esfuerzo por alcanzar, en el ámbito de la historia, un nivel de precisión metodológica y de certeza análoga a aquél que se alcanza en las ciencias de la naturaleza (Ratzinger, 2000: 77-78).

Pero, todo método invita a un cuestionamiento de sus preconcepciones críticas. Al igual que los seguidores de cualquier método, los exegetas no escapan a esta exigencia. Entre los desplazamientos importantes que los conciernen, J. Ratzinger señala el gran lugar tomado hoy por la reflexión acerca de la importancia del acto de lectura, del compromiso del lector en su relación al texto ${ }^{5}$ (Vidermann, 1977).

\footnotetext{
${ }^{4}$ « Las pruebas materiales siendo inciertas o contradictorias [...] se reconstituyen sin la sombra de una duda, los móviles y el encadenamiento de los actos; hacemos como los arqueólogos que van recogiendo viejas piedras en las cuatro esquinas del campo de excavaciones, y con su cemento moderno ponen de pie un delicado descanso de Sesostris, o aún más reconstituyen una religión muerta hace dos mil años sacando del viejo fondo de la sabiduría universal, que no es hecho sino de su sabiduría elaborada en las escuelas de la 3era. República ». R. Barthes, 1957: 53.

${ }^{5}$ «El texto se convierte en el lugar de una experiencia singular y privilegiada, de una recreación en donde
} 
Pero, denunciar la ilusión positivista de la exégesis histórico-crítica como lo hace J. Ratzinger no puede significar una identificación, sin más, entre las prácticas científicas y las preconcepciones "ideológicas" de los investigadores. En efecto, esta identificación hace también el juego del relativismo y olvida el carácter profundamente histórico de nuestra fe. Las prácticas científicas implican también una parte de racionalidad irreductible que no puede considerarse como nada y que permite que la ciencia avance. Del seno mismo del conflicto del cual la figura de Jesús era el objeto, la exégesis histórico-crítica ha surgido progresivamente como una auténtica disciplina intelectual. Al mismo tiempo, poco a poco se volvió imposible decir"absolutamente cualquier cosa" sobre Jesús. Sin duda cada exegeta aborda a Jesús en virtud de sus preconcepciones pero al final termina por tropezar con la resistencia que el texto neotestamentario opone a sus proyecciones idealizantes.
En efecto, quedarse en "una crítica de la razón crítica" sería por una parte olvidar el carácter histórico no solamente de la teología, sino de la propia fe, y por otra, menospreciar el trabajo titánico que hombres y mujeres han hecho, para abrir el camino hacia una lectura de la Biblia que pueda hacer oír hoy la Palabra de Dios en las ágoras de nuestras sociedades secularizadas 6 . Los métodos científicos no pueden reducirse a las preconcepciones de los investigadores, tienen una singularidad irreductible que permite a la ciencia avanzar. J. I. Marion denunciaba, hace algunos años, la tendencia actual a reducir la cuestión de la verdad a la cuestión "¿de dónde hablas?" con el fin de descalificar por principio toda posición. Tendencia que califica de "nihilista".

En el ámbito de la verdad, donde la situación ideológica se hace patente con respecto a las ciencias humanas y a las ciencias sociales: ¿cada doctrina debe someterse, prestamente, a una interroga-

cada lector puede convertirse en el centro, a condición de que quiera salir de esta pasividad que lo empobrece, donde se aísla del texto cuyo sentido se le escapa siempre en gran parte y necesariamente ya que establecido por el autor, pertenece únicamente al autor, el lector no tiene ningún lugar. Que el lector aprenda que no es el espectador maravillado o aburrido de una historia hecha en otro lugar con la que no tiene nada que ver. Que sepa solamente que el texto le habla de sí mismo y de su propia historia y enseguida aparecerá la pluralidad de sentidos posibles». S. Vidermann,1977: p. 43.

${ }^{6}$ P.-M. Beaude señala, por ejemplo, que el método crítico e histórico pone el creyente en harmonía con la cultura de su tiempo. «En la cultura contemporánea, la historiografía juega un papel decisivo. Es a través de ella que nuestra empresa maneja gran parte de su relación con el pasado. Prescindir del enfoque histórico-crítico es correr el riesgo de dejar que se diga cualquier cosa y se pierda la memoria [ ... ] El enfoque evita las trampas del fundamentalismo [ ... ] y permite desarrollar una teología dónde la salvación de Dios encuentre la historia según las leyes de una encarnación real de la Palabra » P.-M. Beaude, 1992 : 5. Cf. P. Gibert, 1995 : 371-384. J. Zumstein, 1994: 51-67. 
ción sobre aquel o aquellos que la sostienen (como es la cuestión siniestramente célebre: ¿de dónde hablas?), que hace explícitamente el salto sobre la verdad misma, de hecho o de teoría7 (Marion, 1992: 14).

Además, los exegetas de hoy son cada vez más sensibles a estos cuestionamientos, aunque siguen desconfiando de las críticas que podrían hacer creer que la exégesis histórico-crítica habría cumplido su tiempo ya sea porque otros métodos comienzan a sustituirla o, más socarronamente, porque se asemejaría a "la montaña que concibió un ratón".

Si era saludable criticar las preconcepciones de nuestras exégesis y también de nuestras teologías, nos parece que un malentendido radical sigue envenenando nuestra exégesis y nuestra teología. No pretendo silenciar la desconfianza recíproca entre teólogos y exegetas, pero nos cuesta calificarla de "separación total"8 (Ratzinger, 2000). Nos parece que hoy por hoy asistimos a la búsqueda sincera de los unos y de los otros por encontrar un punto de equilibrio, intelectualmente aceptable que los haga servidores de la Palabra y no simplemente descifradores de un texto.

Queremos, en las páginas que siguen, buscar un camino de reflexión desplazando la cuestión de la relación dogmática-exégesis a un cuestionamiento de nuestra manera ampliamente historicista de acercarnos aún hoy a la Escritura. Tenemos que tomar conciencia de la humanidad de la escritura como "ficción", como "obra literaria", único camino para hacer acceder la singularidad del recuerdo y la particularidad del acontecimiento al universal, capacidad que genera una complicidad con el dogma. Sin olvidar que no hay ni Escritura ni Dogma fuera de la paradidosis de la Iglesia que vuelve viva a las comunidades que los forjó, que los produjo y que los porta. Las primeras comunidades no extrajeron su Escritura y su Dogma de un acto de exuberante imaginación, como lo pretendían los grupos gnósticos, sin ninguna relación con lo real, sino de la práctica de una auténtica anamnesis de su Señor Resucitado en la confesión de fe de que Él es, no solo la última palabra del Padre, sino su Palabra absoluta y definitiva.

\footnotetext{
7 J.-L. Marion, 1992: 14. Marion analiza también lo que pasó con los otros dos trascendentales -lo bueno y lo bello- en el régimen nihilista de nuestro pensamiento actual. Y sostiene la oportunidad que representa el cristianismo para la razón proclamando una verdad independiente del consenso. Sobre este tema volveremos más adelante.

${ }^{8}$ Cfr. J. Ratzinger, 2000:76.
} 


\section{EL LENGUAJE, CONSTRUCTOR DE LO REAL}

Lo dicho anteriormente nos hace tomar conciencia de la mediación lingüística, del grosor del tejido textual, de la carne del texto en la "nominación" de un acontecimiento dado. Esta toma de conciencia es primera con relación a la mediación comunitaria.

... la toma de conciencia de la distancia entre el texto y su referente, aquí presuntamente histórico, es función de la interpretación, es decir, de una lectura actualizada que, en el caso de los métodos históricos, desea comprobar qué tipo de vínculo se establece entre el texto propuesto, su contexto de producción y el "real" avizorado [... ] [ pero ] la historia es demasiado fragmentaria para apoyar la tarea que se le había asignado. Jesús no es domesticable por la ciencia, aunque esta tenía por objeto acuñarlo en su figura originaria, fuente de su universalidad presente [... ] la toma de conciencia de la ficción [es ] indispensable para una buena comprensión del camino de Jesús tal como lo reportan los Evangelios (Duquoc, 2000: 494,502).

En definitiva, lo que está aquí en juego es la toma de conciencia seria de la distancia considerable entre el referente histórico señalado y su consignación literaria. Una vez que el historicismo de nuestras cristologías contemporáneas ha sido denunciado y que el efecto de espejo entre el dato literario y lo real de lo que es invitado a señalar ha sido roto, hay que leer el texto evangélico como texto literario, construido; en consecuencia, creador de su efecto de sentido, y no como la simple trascripción escrita de las aventuras épicas de Jesús. "Lo que ocurre" no puede decirse sin la palabra que lo constituye en "acontecimiento", y, en consecuencia, lo manifiesta en la diferencia que le da sentido. El acontecimiento es distinto de $y_{;}$como W. Pannenberg lo ha señalado, está en relación con, solo así viene a ser significante. Hay entonces siempre un necesario desfase entre los relatos y lo que ha ocurrido. Esta distancia no nos permite decir que estos relatos sean "infrahistóricos" ya que rigen su relación con la historia de una manera diferente del historicismo. Su dificultad es justamente que se amasan a menudo de demasiada historia.

Un poco a la manera de esos documentales de historia que recogen en dos horas las imágenes demasiado verdaderas de una aventura auténtica. La película puede ser, a la vez, perfectamente objetiva recordando un pasado inevitable (ya que lo que se hizo no puede no haber sido hecho), y completamente construido en función incluso del historiador que lo firma y del mundo donde este vive. La "retrodicción" es un éxito cuando el lector- espectador se deja llevar por la imagen hacia el mundo de la historia. Por su parte, el colega de nuestro cineastahistoriador reconoce, cuando proceda, 
el valor objetivo de esta retrodicción imaginaria; pero al mismo tiempo, entiende inmediatamente todos los"desplazamientos de la historia" que se acumulan en el episodio representado. Puede entonces hacer estallar la película, para distinguir mejor la historia más allá de la imagen de la historia (Perrot, 1982: 56).

Como ya lo dijimos, a pesar de los seísmos que la exégesis histórico-crítica ha producido en nuestra fe, la mentalidad común sigue creyendo, como W. Pannenberg, por ejemplo, que entre todos los saberes actualmente disponibles, el saber histórico es el mejor, quizás el único apto para evaluar la verdad de las Escrituras ${ }^{9}$. Sostenemos firmemente esta convicción, por ejemplo, que el evangelio no es una leyenda piadosa. Para salir "bien parados" del debate público alrededor de la figura de Jesús, tenemos dos opciones: la primera, al igual que W. Pannenberg, animados por la idea de que los únicos testimonios verdaderos son aquellos cuya exactitud puede ser establecida por la ciencia de la historia, hacemos inconscientemente una selección liberadora entre lo que es "verdadero" y lo que es "mítico"; o la segunda, más conscientemente nos aferramos neuróticamente a la historicidad de cada relato con la esperanza que un día la ciencia histórica podrá confirmarlo todo, de la curación del ciego de naci- miento en Jerusalén hasta el ahogamiento de la piara de cerdos en el mar de Galilea. Pero, en los dos casos continuamos leyendo los evangelios como un manual historiográfico, un poco suavizado por el mito, pero historiográfico de todas maneras. En el pensamiento de W. Pannenberg, esto constituye una especie de principio "epistemológico" de nuestras cristologías que no solo determina el tipo de respuestas establecidas, sino, lo que es más grave, condiciona el tipo de preguntas que planteamos a los textos de la Escritura.

Si un tal marco epistemológico debe criticarse, no es en absoluto denegado de razón. No es simplemente el fruto de la ingenuidad de la gente sencilla, sino a menudo el fruto de una reflexión que se quiere teológica. Si la Biblia, el Antiguo Testamento (AT) y el Nuevo Testamento (NT) se presentan como una recopilación cuya intención explícita es dar testimonio de la alianza de Dios con los hombres y en consecuencia de la intervención de Este en la historia haciéndose un hombre de nuestra historia (Jesús de Nazareth que muere "bajo Poncio Pilato"), la primera cosa que es necesario reconocer es que no se honraría la Escritura, al menos, tal y como se da a sus lectores si se la recibiera a priori como una serie de fábulas sofisticadas o relatos míticos. La segunda

${ }^{9}$ En lo que se refiere a la teología historicista de W. Pannenberg Cfr. entre otros Pannenberg, W, 1967: 52 ss. 
epístola de Pedro lo pone ya de manifiesto: "ya que no es siguiendo fábulas sofisticadas que les dimos a conocer la potencia y la llegada de nuestro Señor Jesucristo, pero porque nos convertimos en testigos oculares de su majestad" (2 P 1,16).

Someter la verdad de las Escrituras al examen de la crítica histórica, es pues para muchos cristianos la única manera de tomar en serio esta pretensión del Libro de no ser una mitología. Lejos de poner en entredicho la dimensión histórica de "eso" de lo que hablan las Escrituras, me parece que otra vía puede abrirse delante de nosotros.

Es precisamente porque, entre otras cosas, un tal fundamento es reconocido y aceptado, que conviene preguntarse si el marco epistemológico del que acabamos de hablar y que criticamos en W. Pannenberg es el mejor adaptado para tratar la cuestión que se plantea respecto a la verdad de las Escrituras.

Una posibilidad se presenta: abandonar el combate en torno a la oposición entre el Jesús de la historia y el Cristo de la fe, y dirigirse hacia una interpretación que privilegia otro acceso a lo real, la ficción. El texto neotestamentario no es un reportaje de hechos diversos, susceptibles de ser el objeto de un informe policial, es el resultado de una elaboración literaria para sacar a la luz el sentido de los hechos, acontecimientos, palabras que caerían , sin esta puesta en escena, en la trivialidad, el mito o lo maravilloso. El texto entra en el orden de la ficción, separándose al mismo tiempo del mito, el cuento y la fábula. Es resultante de una voluntad individual o colectiva de evidenciar en el lenguaje lo que se tejía en lo cotidiano y eventual ocultándose al mismo tiempo. Los libros apócrifos orientan hacia esta dimensión sin honrarlo plenamente, y a veces pervirtiéndolo (Duquoc, 2000: 503).

Si la verdad anunciada por el NT considerado en su conjunto, es el propio Cristo, más exactamente que el hombre Jesús que se pretendió el Enviado es realmente Cristo y Señor, Hijo del Padre, cuya muerte y resurrección revelan que por Él y en Él la vida eterna se da a los hombres, se deduce fácilmente que las verdades de la ciencia histórica son completamente impotentes a sostenerlo o a refutarlo. El NT no es un libro histórico en el sentido moderno de esta palabra, es el testimonio, portado por la fe cristiana, del encuentro de un hombre que apareció en nuestra historia. Ahora bien, al poner a un lado la historia, incapaz de pronunciarse sobre la cuestión de fondo, no queremos poner en entredicho la eficacia del acontecimiento de Jesucristo en la historia ya que el NT es una interpretación auténtica de un acontecimiento histórico. Lo que nos interesa es hacer surgir otra cuestión compartida, o, al menos, que deberían tener en común la historia y la teología: ¿cómo los discursos en 
busca de la verdad asumen la diferencia radical que separa y distingue lo real de la realidad? Esta diferencia no es el fruto de una teoría metafísica particular, se impone en cuanto el lenguaje no es un simple instrumento del hombre, según la representación común del conjunto de la tradición filosófica, sino que debe ser reconocido como mediación, como fundación de lo humano (Chauvet, 1987).

En un esquema "instrumentalista" se cree que el sujeto está en una relación inmediata a lo real; y que este le corresponde en el espíritu de manera natural como una copia perfecta bajo la forma de imagen mental de representación o de concepto; y es eso que permite al sujeto comunicarse enseguida con otros, o comunicarse a sí mismo como a otro, lo real. Se tiene la pretensión de alcanzar la inmediación de la "cosa" como una presencia plena de sí a sí en un proceso de transparencia total.

El sujeto humano es colocado (al menos lógicamente) antes del lenguaje presuponiendo así un sujeto ideal que estaría fuera del lenguaje, por lo tanto, fuera de la mediación, es decir, finalmente fuera del cuerpo y fuera de historia ya que lo que regula la concepción instrumental del lenguaje, es la preconcepción que las mediaciones sensibles del lenguaje constituyen obstáculos a la verdad. Es precisamente esa preconcep- ción que se ha puesto en cuestión a través de la revolución epistemológica operada por las ciencias y la filosofía contemporánea del lenguaje. En lugar de ser obstáculo a la verdad, las mediaciones sensibles del lenguaje, del cuerpo, de la historia, del deseo, constituyen el medio mismo en el seno del cual el ser humano adviene a su verdad y, así, corresponde a la Verdad que lo solicita.

La comparación del lenguaje con un instrumento (...) debe llenarnos de desconfianza, como toda noción simplista con respecto al lenguaje. Hablar de instrumento, es poner en oposición el hombre y la naturaleza. El pico, la flecha, la rueda no están en la naturaleza. Son fabricaciones. El lenguaje está en la naturaleza del hombre, que no lo ha fabricado. Somos siempre propensos a esta imaginación ingenua de un período original en donde un hombre completo se descubriría un similar, también completo, y entre ellos, poco a poco el lenguaje se elaboraría. Eso es pura ficción. No vemos nunca al hombre separado del lenguaje y no lo vemos nunca inventándolo. No alcanzamos nunca al hombre reducido a sí mismo e ingeniándose a concebir la existencia del otro. Es un hombre hablante que encontramos en el mundo; un hombre hablante a otro hombre, y el lenguaje señala la definición misma del hombre ${ }^{10}$ (Benvéniste, 1996: 259).

${ }^{10}$ E. Benvéniste, 1996: 259. K. Rahner dice exactamente lo mismo: «Nuestra palabra es más que un pen- 
El lenguaje es contemporáneo del hombre, de la humanidad como tal; comienza con él, y con cada uno individualmente. Si el ser humano existió antes de haber inventado el fuego, el pico o la flecha, no pudo existir antes del lenguaje y en consecuencia, antes de la cultura. No hay sujeto sino hablante, y hablando a otro sujeto-hablante. Para poder "inventar" el lenguaje, hay que pensar en ello, pero, para poder hacerlo es necesario ya estar en el lenguaje. En ese sentido podemos decir que "el lenguaje señala a la definición misma del hombre" y que, como lo añade el mismo E. Benvéniste," es en y por el lenguaje que el hombre se constituye como sujeto". El mundo viene a nosotros siempre ya dicho, formateado en los discursos culturales. Es necesario romper con la falsa inocencia de un mundo dado, anterior al lenguaje y que supone a veces el recurso a la historia en teología. El lenguaje es "mediación", es decir, el medio matricial en el cual adviene el sujeto. Toda relación del sujeto a lo real, toda relación propiamente humana o significante es mediatizada, construida por el lenguaje, y de manera más amplia, por la cultura, y es precisamente construyendo lo real como "mundo" que el sujeto se construye como sujeto.

El "real" es así un efecto del lenguaje, lo que surge como otro y que este no puede ni simbolizar, ni representar completamente. Es más exactamente correlativo al lenguaje, dependiente de este por una relación que al mismo tiempo es de disyunción y de conjunción. Adviene, al borde extremo de este orden de "realidades" que construye, bajo forma de representaciones, el poder imaginario, simbólico, del lenguaje. "Imaginario" no significa ilusorio o falso ${ }^{11}$ (Perrot, 1982). Se designa así este orden de "re-

samiento: es un pensamiento encarnado. Admitida la doctrina escolástica de la unidad sustancial de cuerpo y alma, la palabra es más que una simple exteriorización sonora de un pensamiento que no precisa de este silbido animal para existir y del cual se sirve para señalarse, convencionalmente nada más, en esta bruta animalidad en que nosotros, «espíritus», nos vemos forzados a desenvolvernos. No, la palabra es la corporeidad en que primariamente existe, esculpiéndose, aquello que ahora pensamos y experimentamos. Mejor: la palabra es el pensamiento corpóreo (no solo la corporeidad del pensamiento), y por lo mismo es más que el pensamiento y originariamente anterior a él, como el hombre, uno y total, supera y antecede al alma y al cuerpo individualmente considerados». K. Rahner,1961: 332.

${ }^{11}$ "La narración transmisora de la palabra no es más que la exposición visual del movimiento de la palabra evocada. Tomemos el ejemplo de Mt 19,13-15. El relato, sumamente esquemático, que rodea la palabra («dejad a los niños; no les impidáis que se acerquen a mí») se limita a exponer visualmente el movimiento del logion: la palabra lleva en sí misma su propio relato. Por eso, no debemos decir precipitadamente, con Bultmann, que ese relato es pura invención. Otra forma de «visualización», más difícil de entender para un espíritu occidental, es la de la convicción de fe que se expresa en el lenguaje plástico del judeocristianismo. El relato de las tentaciones de Jesús, según Mt 4,1-11 o Le 4,1-13, nos ofrece un ejemplo notable a este respecto. En toda la vida de Jesús no hay nada más seguro históricamente que esas pruebas, si bien el relato las expresa en un lenguaje de imágenes para que cobren vida a los 
alidades" que el discurso construye pretendiendo hacerlos coincidir con la mayor exactitud posible a lo real mismo. En este sentido, todas las ciencias son imaginarias y lo son aún más ya que su pretensión de exactitud es mayor. No pudieron ni pueden desarrollarse de otra manera. No obstante, se vuelven "ilusorias" -por más exactos, verificables y eficaces que sean sus resultados- cuando trabajan olvidando completamente esta alteridad de lo real que escapa a toda forma de representación y simbolización absoluta.

Ahora bien, como lo vimos, este olvido es, en el fondo, el olvido del sujeto humano, puesto que es sobre él que lo real como efecto del lenguaje hace pesar todo su peso. Olvido de la división que lo constituye en sí mismo, encerrado desde antes de su nacimiento entre la carne y eso que lo representa en los significantes del lenguaje. Ya que la primera manifestación de lo real con la cual el sujeto choca es el propio cuerpo de carne, o más bien, la carne viva y mortal que, porque está vinculada íntimamente con el lenguaje, se erige radi- calmente en un otro al límite de este, pero que también con ese mismo lenguaje al que está ligada constituye el cuerpo, cuerpo del sujeto y alianza de carne y de

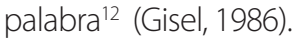

Si la exactitud es ilusoria porque olvida la división del sujeto, este último no es, sin embargo, impotente para acercarse a la división que lo constituye, ni condenado a discurrir en el olvido de lo real cuyo carácter extraño se impone a sí mismo como su parte más íntima. Habla en efecto. Y hablar es estar al borde de lo real, es, por el rodeo de las figuras, acercar y significar como absolutamente irrepresentable este real que, de ser tal, no podrá nunca decirse. Esta es la razón por la cual, si la verdad tiene algo que ver con lo real la literatura -la de todas las épocas y de todas las formas, oral o escrita- es seguramente mucho más apta y mejor armada que los discursos de la exactitud para aventurarse en la búsqueda de lo que, en realidad, no puede sino decirse de manera incompleta. No nos enfrentamos nunca a un universo físico que nos sería heterogéneo, sino a un

\footnotetext{
ojos del lector. Pero ese lenguaje no ha sido elegido arbitrariamente: está elaborado a partir de la Escritura. Otra forma es la de los relatos de milagro, que exponen la praxis cristiana mediante la anamnesis visualizada de las acciones salvadoras del Señor ». Ch. Perrot, 1982: 251.

12 « La distancia que [la Escritura] marca en relación con el acontecimiento del cual da testimonio no es reducible: no se puede ir antes de los textos para descubrir una verdad más pura, como despojada del peso de humanidad propio de todo testimonio. La distancia es al contrario elemento constitutivo del dato de la Escritura: irreductiblemente testimonio dado a eso que ella no es (pero que lo confiesa) y advenimiento de la humanidad verdadera. La verdad cristiana ignora así toda inmediatez de partida. Solo la diferencia entre el texto y la palabra así recordada debe permitir al texto ser revelación: reenviando a Dios ( Palabra) que ahí se dice, en el centro, pero indirectamente, de manera incógnita, y al hombre ahora suscitado como creyente y testigo». P. Gisel,1986: 66.
} 
mundo siempre lleno de significados, siempre ordenado, siempre socialmente arreglado. En ese sentido, las mediaciones sensibles, culturales e institucionales no son tampoco obstáculos que sería necesario descartar idealmente para ir hacia la verdad. Constituyen al contrario, incluso en sus ambi- güedades, el medio en el seno del cual el ser humano adviene a su propia verdad dejándose solicitar por la Verdad, siempre más grande.

El género literario elegido [llamado Evangelio] no privilegia ni lo que se nombra hoy como "Jesús de la historia" ni lo que se define por "Cristo de la fe", esta distinción, legitima en una interpretación crítica moderna, no tiene sentido en su redacción. Los evangelistas describen un itinerario que es invadido de un conflicto del que la muerte será la sanción. Se esfuerzan en significarlo literariamente como la revelación de lo que está en juego: la verdad difícil del vínculo al Dios de Israel. Para este objetivo, el reporte estricto del acontecimiento no tendría ningún efecto. La ficción era necesaria para la puesta en coherencia con lo que está en juego revelado en el proceso; movimientos, actos y discursos del Nazareno. La fe tenía que clasificar y construir, contar no según los criterios de los cronistas, sino según la fuerza evocadora de los novelistas. Leer así el texto permite escapar a menudo al imperialismo positivista del antiguo método histórico-crítico y a la decepción mítica de R. Bultmann (Duquoc, 2000: 504-505).
El texto evangélico debe leerse en su fuerza creativa y en sus potencialidades interpretativas. No se trata de establecer la lista de las respuestas que dirían una a una las verdades de la Escritura, se trata de responder a la verdad cuando esta viene a revelarse en la articulación de la letra y el cuerpo, de la escritura y el encuentro, de la ausencia y la presencia, de la espera y de la venida, de las figuras y de su realización. El Cristo de la fe no devalúa al Jesús de la historia y el Jesús de la historia no evacua como un a priori al Cristo de la fe.

La ficción salva el acontecimiento de su encierro en el hecho anecdótico, conecta los hechos de tal modo que, por construcción literaria, un sentido con valor universal, se da a leer. El referente al acontecimiento impide que la ficción se transforme en cuento o ceda a la imaginación mítica. Los relatos evangélicos se sitúan en este entredicho: el acontecimiento como horizonte necesario, imperceptible debido a su contingencia y su carácter no repetitivo y la construcción literaria como tentativa de generar un sentido a partir de la construcción de la trama de los hechos. El relato impone una estructura y libera un sentido.

La "crítica de las formas" nos volvió sensibles al hecho que los evangelios, tal como los conocemos hoy, no son una pura yuxtaposición azarosa de fuentes dispares sino el fruto de un verdadero 
trabajo de creación literaria, a partir, por supuesto, de fuentes independientes, pero que han sido retocadas por el autor del evangelio para hacerlas entrar en la intriga de su relato. Cristo nos ha sido narrado: citas, alusiones, aproximación tipológicas, reanudación de temas y figuras muestran la intensidad con la que, la construcción de la trama del acontecimiento Jesús, utiliza abundantemente la Escritura, para darle su riqueza semántica al texto evangélico, como por ejemplo, el Servidor Sufriente de Isaías, el Justo abandonado del SI. 22, el Señor del SI. 110, el Rey David y su tumba, el Hijo del hombre de Daniel, el nuevo Adán...

... los evangelios son "producciones eclesiales" que recogen materiales de épocas y medios diversos con el fin de responder mejor a las necesidades concretas de una iglesia determinada: Roma (Mc), Antioquía (Mt) y otros. ¡Son "textos vivos"! (Perrot, 1995: 33).

\section{LA ESCRITURA: UNA PALABRA ORIGINAL ( $U R W O R T$ )}

Nos olvidamos a menudo de leer los relatos evangélicos tal y como "fueron reescritos" por los evangelistas. Un vínculo literario es creado entre los acontecimientos relatados, las palabras referidas, los gestos escogidos y la aparición de un sentido para todo lector, individual y colectivo. En esta dialéctica entre el hecho contingente y la construcción literaria, el acontecimiento, incluso si es imperceptible en su singularidad, es decisivo para el sentido. Los autores de los primeros símbolos de fe, por ejemplo, lo habían comprendido al arraigar en la historia general del Imperio, por la mediación de una de sus autoridades, Poncio Pilatos, el asesinato judicial de Jesús de Nazareth. Un cambio de perspectiva es necesario.

Antes de hablar de fuentes y dependencia literaria, conv[iene] de aprehender los textos como textos, conjuntos en los cuales los temas pueden seguramente deri- var de fuentes variadas, pero deben sobre todo ser examinados en el papel que juegan. La "crítica literaria" sola no basta, ya que recurre sin cesar a las"intenciones" de modificaciones, que son hipotéticas a un grado muy alto (Léon-Dufour, 1971: 150).

El valor de los relatos evangélicos tal y como los conocemos no puede reducirse a ser la caja fuerte en la cual la verdad se oculta en forma de un texto primitivo y en consecuencia, histórico, que es necesario descubrir absolutamente. Seguramente, los esfuerzos para situar el Sitz im Leben - a pesar de todo lo que pueden tener de arbitrario- pueden ayudarnos a comprender mejor un texto, pero no podemos reducir nuestra comprehensión del texto a ello. Es necesario colocarnos frente a él como lectores y no como arqueólogos que con una fina brocha intentaran delicadamente remontar los siglos en busca de un 
texto primitivo que no pudiera ya ser comprendido, ya que no guarda con nosotros ninguna relación viva. Los vestigios aislados de los textos evangelios no pueden sino hacerse polvo. El hecho que incluso el trabajo más docto a nivel histórico o lingüístico sobre, por ejemplo, la reconstrucción de la fuente $Q$, o sobre la vida de Jesús, no podrá nunca ocupar el lugar de los evangelios en nuestras asambleas litúrgicas debe hacernos reflexionar. Este hecho no es la señal de la esquizofrenia cristiana denunciada por E. Troeltsch sino un revelador de lo que es la Escritura para la lógica del cristianismo.

Además, es necesario tomar en serio la especificidad del género literario de los evangelios. Marcos no solamente escribió un evangelio en vez de un manual de historia o de una novela biográfica de un héroe, sino que inventó el género. La manera de preguntar históricamente un documento varía según su "género literario". No leemos una novela como si se tratase de una recopilación de poemas. Y además, cada autor adapta o amplia los géneros ya existentes respetando, al mismo tiempo, un mínimo de reglas que facilitarán la comunicación con el lector. G.N. Stanton en su libro"Palabra de Evangelio?" (1997) supo expresar esta exigencia de una manera muy provocadora a partir del desconcierto que la llegada del Codex de los evangelios habría producido en la biblioteca de Éfeso:
En 110, se creaba una espléndida biblioteca en Éfeso a la memoria de Gaius Julius Celsus que fue gobernador de la provincia a partir de 105-107. La biblioteca de Celsio, nombre bajo el cual se la conoce ahora, [... ] es uno de los monumentos más impresionante de la antigua Éfeso. Contenía 12.000 rollos conservados en las repisas de nichos construidos en las paredes de la habitación central [.. en la generación que vio la apertura de esta biblioteca el cristianismo comenzaba a llamar la atención (a menudo crítica) de los medios "doctos" de la región. Es pues probable que ejemplares de algunos de los evangelios hayan llegado hasta la biblioteca. Esta llegada de los evangelios habría sido para los bibliotecarios un verdadero rompecabezas. ¿Dónde clasificarlos? ¡Se presentaban bajo la forma de un Codex (un libro) y se había concebido la biblioteca para albergar millares de rollos! [... ] los cuatro evangelios se habían unido juntos en un único Codex a mediados del siglo II (o quizá antes) [... ] el bibliotecario encargado de las adquisiciones se encontraba ante un problema aún más serio: ¿en qué sección colocar los evangelios? ¿En las historias, o novelas, o biografías, o tratados religiosos? La decisión del bibliotecario debía despertar en el lector una inquietud particular (Stanton, 1997:168).

En ese sentido es bueno recordar cómo los Padres llamaban a los relatos evangélicos. Con respecto a Marcos, Papias al referirse a "lo que decía el presbí- 
tero" habla de apomnemoneuo (acordarse) ${ }^{13}$ (De Césarée). Justino escribió: "Marcos, dicen, se acordaba de las Memorias de los Apóstoles (apomnemoneimata tu apostolôn) que se llaman Evangelios"14. Según Papias, el mismo Pedro no presentaba en su predicación el relato completo de las acciones de Jesús y su enseñanza: adaptaba las tradiciones, para responder a las necesidades de sus auditores. Al leer de cerca las observaciones de Papias, uno se da cuenta que ya reconoce la existencia de una distancia entre Marcos y la vida de Jesús: Marcos interpretó la enseñanza de Pedro; Pedro adaptó las tradiciones relativas a Jesús. Papias reconoce también explícitamente que Marcos no era un testigo ocular personal de la vida de Jesús. Pero, en la frase que sirve de prólogo al evangelio según Lucas, el autor destaca que se inspiró en el trabajo de estos antecesores que fundaron sus relatos sobre tradiciones transmitidas por testigos oculares que son a la vez Ministros de Palabra. En otros términos, los testigos oculares no aportan recuerdos "neutros" sobre los acontecimientos de la vida de Jesús. Sobre la base de su experiencia personal en el seno de la ekklesia, proclaman su significado transmitiendo una tradición interpretada.
Loveday Alexander recientemente estudió el prólogo de Lucas en su contexto del siglo I greco-romano y judío y hace notar la diferencia en el empleo de la expresión "testigo ocular" en griego y en el tiempo moderno. Para nosotros, un testigo ocular, en contexto judicial, es a menudo, inapreciable: se trata de alguien que se encontraba allí (en general por casualidad) en el momento en que un incidente se produjo. En cambio, la palabra griega no se emplea en este sentido. Una mejor traducción de lo mencionado por Lucas de "testigos oculares" podría ser: "los que tuvieron una experiencia personal, de primera mano, los que conocen los hechos de primera mano (Alexander, 1993: 116-125).

Es pues a un "trabajo de memoria" al que se dedicaban los evangelistas. El relato no es pues una pálida copia del original que sería la experiencia histórica o una débil y decepcionante imitación de la realidad de la que habla. Es el lugar de una operación poética necesaria, que refigurando la relación a la realidad, le permite dar sentido. Entre el creyente de hoy (o el simple lector) y la experiencia "viva" vivida por los apóstoles está el escrito, que pone orden a los hechos sin lo

\footnotetext{
${ }^{13}$ «Y el anciano decía lo siguiente: Marcos, que fue intérprete de Pedro, escribió con exactitud todo lo que recordaba, pero no en orden de lo que el Señor dijo e hizo. Porque él no oyó ni siguió personalmente al Señor, sino, como dije, después a Pedro. Este llevaba a cabo sus enseñanzas de acuerdo con las necesidades, pero no como quien va ordenando las palabras del Señor, más de modo que Marcos no se equivocó en absoluto cuando escribía ciertas cosas como las tenía en su memoria. Porque todo su empeño lo puso en no olvidar nada de lo que escuchó y en no escribir nada falso » Papias citado par Eusebio. Cf. Eusèbe de Césarée, Histoire ecclésiastique, I, 39, 15. Paris : SC 31, p. 156-157.

14 Justino. I Apologie CVI.
} 
cual la memoria no se haría y el sentido no se propondría. Volveremos a esto más adelante.

¿Pero se puede utilizar la palabra ficción? Es seguramente posible, a condición de descartar desde el principio un malentendido sobre el sentido de esta palabra. Hoy día, la ficción se pone más bien del lado de la historia inventada en oposición a la historia "seria". Se habla de ficción en la televisión para las series novelescas, se habla de las novelas en términos de literatura de ficción. Si entiendo la palabra "ficción" en el sentido de obra novelesca no es de gran ayuda para hablar de los evangelios.

Los evangelios no son novelas, cuentos imaginados para seducir al lector, a menudo con algo de color, para hacer buena impresión. Sólo el relato de la decapitación de Juan-Bautista entra en esta categoría (Mc 6,17-29 y Mt 14, 312). En la antigüedad, apenas se apreciaba este tópico común de los modernos, la ficción nos instruye sobre la condición humana. (Stanton, 1977: 171-172)

La novela, en efecto, es un género literario relativamente reciente, cuya aparición no remonta, en líneas generales, más allá del Renacimiento. P. Ricoeur comprende "la ficción" como el auxiliar indispensable de toda comprensión del tiempo, del hombre y de la historia. La etimología de la palabra"ficción" (del latín fingere: modelar en la arcilla) nos enseña que se trata de un trabajo de prefiguración, una manera de hacer eso que se quiere expresar, y sin lo cual no se puede expresar nada. La ficción viene a ser el hilo conductor gracias al cual se organiza la realidad, no para representarla (ilusión positivista) sino para presentarla, dejarla ver.

No se puede hablar de un género literario de ficción con respecto a los evangelios sino como literatura, producto de una operación poética (poièsis), de una construcción de la trama de la realidad. El hombre es, sin duda, un ser visitado, hecho por algo que le adviene. Pero, al mismo tiempo, hace y visita eso que le adviene. No hay realidad que no sea atravesada por su palabra y por su acción, y la palabra y la acción son "poiéticas", son un hacer, una creación. No en el sentido que inventen a partir de nada (incluso el artista no lo hace), sino en el sentido que hacen advenir todas las cosas al mundo del hombre.

Esta es la razón por la cual es, seguramente, preferible hablar de " poiética", para designar este poder "de moldear"la realidad reconocido a la obra literaria, un poco lo que K. Rahner llamaba Urwort, "palabra originaria".

Hay también palabras que, a través de una cosa particular, hacen traslucir lo infinito de toda realidad. Son como conchas en las cuales resuena el mar del infinito, por más pequeñas que 
puedan ser. Nos iluminan [...]. Tienen poder sobre nosotros porque son dones de Dios, no fabricaciones del hombre, aunque sea quizá por fabricaciones del hombre, que ellas han venido a nosotros. Las unas son claras porque son planas y sin misterio; bastan a la inteligencia; gracias a ellas uno se apodera de las cosas. Las otras pueden ser oscuras, porque evocan el misterio supraluminoso de las cosas. Suben del corazón y estallan en himnos. Abren las puertas para las grandes obras, y deciden sobre eternidades. Estas palabras que brotan del corazón, que se apoderan de nosotros, que unen por un encanto, las palabras que celebran y que son dadas, querría llamarlas palabras originales. Las otras, podrían llamarse palabras fabricadas, técnicas, las palabras utilitarias ${ }^{15}$ (Rahner, 1964: 269).

Por esta expresión, Urwort K. Rahner no designó simplemente palabras particulares, sino la palabra que saca las cosas de su oscuridad para llevarlas a la luz del hombre. Este poder de"representar" no es la capacidad de mostrar la simple y pálida copia de una realidad que seguiría siendo cada vez más rica que su imitación, sino la refiguración de esta realidad en la operación creativa que es la puesta en escena, el descubrimiento de la palabra original que no deja de velarse en el corazón de nuestras historias. Tal operación, lo vimos, produce una cons- trucción de la trama capaz de suscitar el trabajo de memoria. En el caso de los evangelios, es la experiencia de los apóstoles que habiendo vivido con Jesús de Nazareth, que por la transmisión de todo un material narrativo y figurativo es representado y accede por allí a una condición literaria que aporta la coherencia y lo inteligible, insertada, por el juego de prefiguraciones, en un desarrollo que tiene una lógica en conformidad con el querer misterioso de Dios.

¿Pero después de todo cuándo una historia es "verdadera"? Cuando, a través de los hechos o los personajes mencionados, se dice algo de la verdad profunda del hombre; cuando aquel o aquella que lo dice hace que su relato esté habitado por el peso de su experiencia y de la sabiduría común de su pueblo; cuando lleva a los lectores a hacer la verdad de su propia existencia; resumidamente, cuando los hechos singulares son elevados a un significado universal. La ficción, lo mismo que la historiografía, es capaz de dar testimonio de la verdad y de la complejidad de la historia y de los que hacen la historia. Dando vida al relato, la ficción da la facultad de entrar en el pensamiento de los protagonistas, de describir sus emociones, sus motivaciones y sus intenciones ocultas, de poner de relieve su evolución personal y relacionada. Gracias a la fic-

\footnotetext{
${ }^{15}$ Urwort, formado de Wort, palabra, y del prefijo Ur que significa lo que es a la vez totalmente primitivo, auténtico, profundo, cargado de misterio.
} 
ción, el autor puede introducir al lector en el designio secreto de Dios, denunciar los callejones sin salida donde lo precipitan las elecciones de su pueblo, describir la fineza de la estrategia con la cual pretende reorientar la historia. En el fondo, gracias a la ficción -a menudo más verdadera que la realidad- los autores de la Biblia presentan al lector una meditación sobre la complejidad de las motivaciones humanas y sobre la ambigüedad de los personajes, simplemente porque son dimensiones constitutivas de una determinada visión del hombre, creado por Dios y probando las consecuencias a veces felices, a veces austeras, del ejercicio de su libertad. Es quizá en eso que sus relatos afectan al lector en el corazón mismo de su historia, y hacen la historia. ¡La escritura es así una obra de vida, una obra de amor, una obra de verdad!

El amante que espera para mañana el regreso de la amada no escribe pero si no volvió ni al día siguiente ni los días siguientes, la primera carta señala la primera inquietud, la primera angustia. Es seguramente eso lo que pasó para los hombres de ese tiempo el primer evangelio escrito: una carta durante la separación, la señal de una cita pospuesta (Merejkovsky, 1974: 11).

\section{CONCLUSIÓN}

La poiética de los evangelios es capaz de testimoniar la verdad y la complejidad de la historia y de los que la hacen. Es quizás en eso que el relato evangélico toca al lector en el corazón mismo de su historia, y hace la Historia. Cada vez que el hombre es confrontado a su verdad la más profunda, indisociable de la Verdad, sea a partir de la experiencia del mal radical o de la bondad la más sublime ninguna construcción puramente histórica podrá expresarla con justeza.

J. Semprun hace referencia a un debate entre los supervivientes del campo de Buchenwald inmediatamente después de la liberación. Después de un debate agitado, donde cada participante experimenta la gravedad de la pregunta planteada: " ¿cómo hay que contar para que se nos comprendan?", ellos que habían probado en su carne el peso trágico de la realidad, llegan a la conclusión que "la verdad esencial de la experiencia no es transmisible... o más bien, ella solo lo es a través de la escritura literaria..." y que será necesario para ello, inventar un género literario propio ... ¿No es eso lo que los cristianos hicieron a fines del siglo I?

\footnotetext{
... sería necesario una ficción, pero ¿quien se atreverá? Mejor sería realizar una película de ficción hoy mismo, en la verdad de Buchenwald aún visible...
} 
La muerte aún visible, aún presente. No un documental, digo bien: una ficción... es impensable...

Hay silencio, pensamos en ese proyecto impensable. Bebemos a lentos tragos el alcohol de la vuelta a la vida.

- Si comprendo bien, dice Yves, nunca sabrán, los que no han estado! - Nunca realmente... Habrá los libros. Las novelas, preferiblemente. Los rela- tos literarios, al menos, que superarán el simple testimonio, que darán a imaginar, incluso si no dan a ver... Habrá quizá una literatura de los campos... yo digo bien: una literatura, no solamente un reportaje. (Semprun, 1994: 165-167). 


\section{BIBLIOGRAFÍA}

Alexander, L. (1993 ). The Preface to Luke's Gospel. Cambridge: CUP.

Barthes, R. (1957). Mythologies. Paris: Seuil.

Benvéniste, E. (1996). Problèmes de linguistique généralel. Paris : Gallimard.

Chauvet, L.-M. (1987). Symbole et Sacrement. Paris: Cerf (CF 144).

De Césarée, E. (1952). Histoire ecclésiastique. Paris: Cerf. (SC 31).

Duquoc, C. (2000). «Lintérêt théologique de la quête du Jésus historique». In: RSR 88/4, 492.

Gibert, P. (1995). «L'Exégèse Critique, témoin de l'incarnation ». In Ce Dieu qui vient (sous la dir. de R. Kuntzmann), Paris : Cerf (LD 159).

Gisel, P. (1986). Croyance Incarnée. Tradition-Ecriture-Canon-Dogme. Genève: Labor et Fides.

Léon-Dufour, X. (1971). Résurrection de Jésus et message pascal. Paris: Le Seuil.

Marion, J.-L. (1992). «L'Apologie de l'argument». In COMMUNIO XVII 2-3.
Merejkovsky, D. (1974). Jésus inconnu. Paris: Cerf.

Pannenberg, W. (1967). "Heilsgeschehen und Geschichte". In: Grundfragen systematischer Theologie. Göttingen.

Perrot, C. (1982). Jesús y la Historia. Madrid: Cristiandad.

Perrot, C. (1995). Jésus et l'Histoire. Paris: Desclée

Rahner, K. (1961). "Sacerdote y Poeta". In: Escritos de Teología III. Madrid:Taurus.

Ratzinger, J. (2000). L'Exégèse chrétienne aujourd'hui. Paris: Fayard.

Stanton, G. (1997). Parole d'évangile?. Paris: Cerf.

Semprun, J. (1994). Lécriture ou la vie. Paris: FolioGallimard .

Vidermann, S. (1977). Le Céleste et le Sublunaire. Paris: PUF.

Zumstein, J (1994). «Les enjeux de la méthode historico-critique», in Exégèse et Théologie, Paris : Cerf (LD 158 